\title{
Construction management contracts: law and practice
}

Article

Accepted Version

Hughes, W. (1997) Construction management contracts: law and practice. Engineering, Construction and Architectural Management, 4 (1). pp. 59-79. ISSN 0969-9988 doi: https://doi.org/10.1108/eb021040 Available at https://centaur.reading.ac.uk/4283/

It is advisable to refer to the publisher's version if you intend to cite from the work. See Guidance on citing.

To link to this article DOI: http://dx.doi.org/10.1108/eb021040

Publisher: Emerald

All outputs in CentAUR are protected by Intellectual Property Rights law, including copyright law. Copyright and IPR is retained by the creators or other copyright holders. Terms and conditions for use of this material are defined in the End User Agreement.

\section{www.reading.ac.uk/centaur}

\section{CentAUR}

Central Archive at the University of Reading

Reading's research outputs online 


\title{
Construction management contracts: law and practice
}

\author{
Will Hughes, \\ Dept of Construction Management \& Engineering, University of Reading, PO Box 219, \\ Reading RG6 6AW, UK
}

\begin{abstract}
The context of construction management (CM) reveals that this method of procurement is as much a management philosophy as a contract structure. It is important to consider legal and contractual issues in this context. The interplay between management and law is complex and often misunderstood. Before considering specific issues, the use of contractual remedies in business agreements is discussed. In addition, the extent to which standardising a form of contract detracts or contributes to the success of projects is also considered. The dearth of judicial decisions, and the lack of a standard form, render it difficult to be specific about legal issues. Therefore, the main discussion of legal issues is centred around a recently completed research project which involved eliciting the views of a cross-section of experienced construction management clients, consultants and trade contractors. These interviews are used as the basis for highlighting some of the most important legal points to consider when setting up CM projects. The interviews revealed that the advantage of CM is the proximity of the client to the trade contractors and the disadvantage is that it depends on a high degree of professionalism and experience; qualities which are unfortunately difficult to find in the UK construction industry.
\end{abstract}

Keywords: Construction management, contract drafting, law, procurement, risk apportionment.

\section{Contract structure or management philosophy?}

Construction management (CM) is a procurement system which differs significantly from general contracting. The key organisational difference is that the client contracts directly with a series of trade contractors, thus eliminating the role of general contractor. Many of the functions of a general contractor are thus taken on by the client. A further organisational difference is the role of the construction manager in co-ordinating and managing construction work, in conjunction with a design manager who leads and co-ordinates the design work. 
This relationship typically involves the construction manager in managing the production of design information, while falling short of getting involved with design decisions. As this paper will show, the absence of a main contractor creates contractual liabilities between trade contractors and clients that are unique. There is much variation in current CM practice regarding risk allocation and the patterns of responsibility. The research reported in this paper was designed to discover the extent of that variation to help in developing the UK's Joint Contracts Tribunal's new standard form of Construction Management contract.

The current enthusiasm for construction management seems to stem from a view that traditional approaches to contracting generate adversarial feelings. There is a great danger that the dispositions of risk and responsibility in general contracting can motivate parties to pursue their own interests, over and above the client's needs. Indeed, there is plenty of evidence of self-seeking behaviour;

Architects may find conflicts of interest acting on the one hand as a client's agent and on the other hand as an impartial contract administrator. Payments to contractors can be constrained by the client and consultant team: clients do not always pay promptly and consultants do not always certify fairly (Bingham 1992, Chappell 1989). ${ }^{1}$

Contractors live or die by their cash flow. They find that they are often involved in high levels of sub-contracting, some of which is nominated. The balance between receipts and payments can be manipulated to their advantage by delaying payments to sub-contractors and suppliers. Recent research has shown that only $15 \%$ of sub-contractors are paid on time (Hughes at al 1995).

\footnotetext{
${ }^{1}$ Michael Sallis \& Co Ltd v E C A Calil and Others [1987] 4 Con LJ 125; Pacific Associates and Another v Baxter and Others [1988] CILL 460; John Mowlem \& Co plc v Eagle Star Insurance Co Ltd, Eagle Star Property Management Ltd, Eagle Star Properties Ltd, Phippen Randall \& Parkes Ltd 10-CLD-06-01.
} 
Sub-contractors find that they are far removed from the ultimate users of the things that they install. The integration of their design work into the process is rarely smooth; design warranties, and the liability that goes with them, abound; and the difficulties in getting paid are often sufficient to render firms insolvent.

There is no doubt that the traditional ways of doing business in construction are increasingly inadequate. The Latham Report (1994) is just the latest of many such analyses which have found that contracting per se lies at the root of many of the problems in the industry.

For all sorts of reasons, disenchantment with existing approaches has led experienced clients to explore alternatives. Some commentators claim that all alternative procurement approaches have arisen as a response to deficiencies in traditional systems of contracting (Rougvie 1987). Part of this exploration led to the emergence of Management Contracting, an approach to procurement that was primarily designed to relieve the main contractor of contractual risk so that developer-clients could reap the benefits of shouldering the risks themselves (Murdoch and Hughes 1995). In a buoyant economy, this was a worthwhile approach to the problem, but during recessionary periods, the pricing policies of contractors wipe out any benefits that might accrue from re-distributing risks along the lines of management contracting. Design and build (DB) is a solution which depends upon a DB contractor having all of the necessary design and construction skills within one organisation; a phenomenon that would be rare for complex buildings. The alternative that is about to undergo a surge of popularity is construction management.

Although CM has a significantly different contract structure, its main proponents argue that it is more a new management philosophy than a system of contracting. Successful construction managers and clients are enthusiastic about the approach. Experienced construction 
managers claim that it can take at least 18 months of project experience to move from a contracting background to a CM philosophy. The underlying philosophy is an approach to management which is organic, rather than hierarchical. The absence of the general contractor places the trade contractors in a direct relationship with the client's team, rather than through an intermediary. The construction manager has no contractual liability for the performance of the trade contractors. Such an organic approach is ideally suited, although not limited, to technically complex and speedy projects. Experienced practitioners are worried that by publishing a standard form of CM contract, the gates would be opened for inexperienced people to enter into these kinds of arrangements without the backup of the right kind of management philosophy. This could be a recipe for disaster. Before considering the argument about standardisation, there are some basic issues about the extent to which a contract can be used as a tool of litigation. Typically, commercial contracts are written with the aim of planning what will happen when business relationships fail. This is important because a radically different management philosophy might be compromised by too much emphasis on contractual remedies.

\section{The use of contractual remedies in business deals}

Our research has shown that for CM projects in practice, claims are rare, let alone disputes. There are occasional disputes, but they are few and far between by comparison with more traditional methods of trading. As reported later in the paper, 40 people were asked how they typically dealt with disputes in CM projects. In the majority of cases, disputes are negotiated (see Figure 6). However, a sizeable portion are referred to arbitration or adjudication. This is important because it means that a third party, whether sitting in judgement or simply helping the parties to come to an agreement, needs an accurate record of what had been agreed. Once the parties are in dispute, the record of the agreement becomes very important as the most 
direct route to what they had agreed at the outset. Therefore, regardless of one's own good intentions, it is commercial suicide not to plan for contractual remedies to be used in the event of the other party's failure to perform in accordance with the original agreement. Thus, it is important to use documents that form a useful record of what has been agreed about roles, duties and liabilities. But this has to be tempered with the need not to appear too litigation-conscious, a stance that can prevent goodwill developing during the transaction processes.

\section{Standardisation of contracts}

Although not essential, it is common practice when procuring a building to appoint the contractor on a standard form building contract. These forms, as will be seen, have emanated from various parts of the construction industry and for various reasons. Each of them has a role to play in the choice of strategy. In order for the process to work effectively, it is essential that the standard forms are understood in terms of the way they distribute risk. There are many aspects to the arguments for and against standard forms.

\section{Legislating for the industry}

Drafting committees often express the sentiment that they are legislating for the whole industry. Whatever their reasoning, such an aim is way beyond their remit. It must be remembered that the UK is a constitutional free market. It is well established contract doctrine that the parties to a contract are free to choose the terms of their contract. There are leading cases where this sentiment has been expressed specifically. ${ }^{2}$

\footnotetext{
${ }^{2}$ Eurico SpA v Philipp Bros., The Epaphus [1987] 2 Lloyd’s Rep 215, CA
} 


\section{Similar projects demand similar contracts}

It is interesting to note that the Banwell Report (1964) recommended that the building industry should develop and use a single standard-form contract for all construction projects. This idea has been given a further push recently with a recommendation of the Latham Report that steps should be taken to apply the New Engineering Contract (Institution of Civil Engineers 1993) as the universal standard for the entire industry (Latham 1994). The pursuit of a universal standard contract has fuelled much of the development of contracting in the UK. The aim of standardising building contracts to this extent is simply unrealistic. When the complexity of a modern airport or hospital building is compared with that of a housing development, it is clear that the contractual issues are completely different. For example, delays due to bad weather, a contractor's inability to obtain materials, delays in the supply of information, onerous site conditions, insolvency etc. differ in their likelihood, severity and magnitude. If these issues differ, then the apportionment of the risks surrounding them must also differ. Therefore, different contracts are needed. Unfortunately, the differences in technological complexity and types of client (to name but two of the variables) are so large that the aim of developing a universal standard form is no longer realistic. Clearly, there is a need amongst clients and contractors for different contracts to suit different situations and this conflicts with the equal need for standards to be applicable to as wide a range of projects as possible.

\section{Equitable distribution of risk}

One purpose behind using standard-form contracts is to allocate risks fairly between the parties. The use of a standard form should imply that contractors need not include an allowance in their prices for risks. However, risks are apportioned by any contract, standard or not, and in many circumstances it would be unwise to allocate them in this way. When 
choosing a procurement method the criteria for selection should be studied very carefully and the allocation of risk should be made explicit, rather than implicit. This leads to one of the strongest criticisms of standard form building contracts: the apportionment of risk is rarely questioned and, therefore, becomes implicit. In such situations, the employer is only comparing tenders from contractors competing upon the same pattern of risk apportionment. Therefore, no assessment can be made by the client of the suitability of the form of contract.

\section{Difficulty of understanding contract complexities}

One of the main reasons for standardising the contracts used in building is because the contractual complexities can be difficult to appreciate. Many in the industry feel that the use of a standard form will help to increase familiarity with all the contractual provisions.

Unfortunately, this ideal is rarely achieved, for at least two reasons. First, the standard forms are rarely used as printed. It is common in the industry for people to amend the printed form, by striking out clauses they do not like and adding in their own preferred clauses (Greenwood 1993). The wisdom of this practice is questionable because an amended contract may fall into the category of an 'employer's standard terms of business' for the purposes of the Unfair Contract Terms Act. The effect of this is that any exemption clause created by amending a standard form may be construed against the party who put it forward. Secondly, the structure of the construction industry encourages firms to concentrate on particular types of work. Civil engineers and builders rarely interact. The various groups of consultants can thus fall into the trap of only knowing about one standard form. If this happens, their understanding of the contractual issues involved is very narrow and there is often a failure to appreciate the wider issues in the context of English law. This can lead to misunderstandings which are perpetuated simply because, once such consultants realise how complex the standard form is, they do not wish to add to that complexity by using a different one. The only real answer to 
this problem is to understand the principles of contract law first and then to apply these principles to the standard forms, so that the allocation of risk within each form can be appreciated.

\section{The purpose of contract documentation}

There seems to be a wide range of uses to which contract documents are put. The basic defining aim of a contract is to record accurately the terms of a business agreement. While the vast majority of commerce and commercial law is based upon this assumption, the circumstances of the construction industry are such that the concept of contract often becomes severely distorted. For example, some approach the drafting of contracts as if the primary aim was to set down the management procedures and administrative processes for the work; others take a much more confrontational approach and seek to use the contract primarily as an agenda for litigation and a vehicle for taking an obstructive and uncompromising stance; others see the standard forms as a nationally negotiated prescription of what can or cannot be done by the various participants. On the face of it, perhaps these distinctions are not too important. But, ultimately, construction contracts are subject to the same rule of contract law as any other type of contract. Therefore, it is extremely important to ensure that there is some consistency in the way that different industries draft their agreements and contracts. Contracts are drawn up with the intention of relying upon them in a court of law or arbitration at some point in the future. However, the nature of business is such that a potential trading partner can be put off by too much emphasis on negotiating contractual issues while the bargain is being struck. There is a fine balance between underemphasis and over-emphasis on contract terms during the negotiating process. Both are equally damaging and approaches are needed that will enable business deals to be struck which are recorded more accurately than is currently the case. 


\section{Appropriateness of contract form}

Standardising contract terms enables parties to reduce the emphasis on specific contractual terms during the bargaining process. Thus, they are very appealing. On the other hand, they tend to be drafted by committees representing powerful interest groups in the industry. The danger is that standardisation goes hand in hand with an adherence to outdated methods of organisation and professional patterns of responsibility, regardless of whether these are appropriate to the needs of a particular project or client. It is the failure to identify appropriate roles and a suitable organisational structure that lies at the root of the question of standardisation.

\section{Views of CM practice}

To shed light on the more difficult issues in CM contracts, this section reports some of the results from 40 structured interviews that were carried out as part of a recent research project funded by the UK's Joint Contracts Tribunal. The purpose of the research was to undertake systematic industry consultation and to help the finalisation of the drafting process. The interviews were undertaken to get a wide view of how certain issues were typically dealt with in practice. The same questions were used in all of the interviews, having been developed to elicit responses that would help to clarify certain issues. The JCT working party who were developing the new standard contract had identified a series of issues where more information about common practice would be helpful and where the reactions of experienced practitioners would help to inform the drafting process. Since some of the questions related to partially formed proposals of the working party, it is not appropriate to report the full list of questions here, or the full set of findings. This paper deals with those findings which are of general interest. 
The interviewees were chosen from among the few experienced practitioners of CM in England. They consisted of 8 clients, 9 construction managers, 11 trade contractors, 10 consultants and 2 lawyers. All of the interviewees are extensively involved with CM projects and are very experienced in this procurement method. They were chosen for their knowledge and experience and were asked to express their personal views rather than their perceptions of corporate views. This was because the JCT felt that relevant corporate views had already been taken into account during the processes preceding this research project. In reporting the findings, comments were not attributed to individuals without their express permission. Interviews were recorded, transcribed in full, then summarised. Although this paper is not intended to furnish a complete record of the research, for reasons of confidentiality, many of the general impressions warrant discussion and are worth reporting here.

\section{Experience of practitioners}

There are few clients, construction managers or trade contractors with extensive experience of this procurement method. For example, trade contractors need to develop a much more intensive approach to the management of their own contribution and few have invested sufficient resources in this. Construction managers from a contracting background may have difficulties developing a fundamentally different approach to the management of trade contractors. Similarly, consultants need to develop an approach to design that takes account of design input from trade contractors and of management control by construction managers. Finally, clients, by definition, need to take a much more active role in CM than they would need to in other forms of procurement. The research revealed that some of the interviewees were not completely clear about the differences between construction management and management contracting. In setting up a CM project, a lot of work needs to be done at the outset in terms of identifying precisely what will be required of everyone involved with the 
process. Such preparation is not the norm in traditional approaches and practitioners who are not used to CM may not find it easy to adapt. For all of these reasons, many people in the UK construction industry lack the experience and know-how necessary for successful involvement in a CM project.

\section{Success of projects}

Very few projects have resulted in bad experiences. CM is popular. Clients were generally very happy with CM, with few reservations. The main reservations were that it depended on high calibre people, with a need for all participants to understand the nature of the process and the product. Three clients mentioned that they had had bad experiences due to poor quality people. Two were positive about costs savings (5-20\%). Construction managers were very positive about their satisfaction but four of them identified inexperienced clients as being the main source of difficulty. Trade contractors reported more mixed experiences. Six were generally happy with CM, two of whom cited the benefits of closer relationships with the client. Observations included the extra investment needed to respond to greater demands and the one-sidedness of some of the contracts. Two trade contractors felt that the success of CM was highly dependent on the quality of the client and the construction manager. Of the consultants, five were enthusiastic and three reported dissatisfaction for various reasons such as inter-professional rivalry and unresponsive clients.

A few people mentioned that high profile projects with excellent people tend to be run under $\mathrm{CM}$ so it is difficult to be clear about which is the cause and which the effect.

\section{Project types}

There was a fairly clear message that in principle, CM could be used on any project type. Indeed, some of the interviewees had used this approach with great success on small as well 
as large projects. People who had not tried CM for small projects felt that it would be unsuited to small, slow or simple projects. The most significant exclusion was not project type but client type or project strategy. The role played by the client in CM is so significant as to render the process inadvisable if a client is not experienced. Also, projects where the strategy was inadequately thought through were cited as unsuited to CM. If it is to succeed, CM demands excellent people who know what they are doing and it needs a clear picture of roles and responsibilities from the outset.

\section{Advantages}

The biggest advantage of CM is the proximity of the client to the trade contractors. The clients and trade contractors were equally enthusiastic about their direct and long term relationships with each other. Four of the consultants welcomed early involvement of the trade contractors and better access to the expertise of trade contractors. High levels of control and flexibility were cited by five construction managers, three clients and a consultant.

Seven people commented on the improved relationships; clients mentioning trust and visibility; a construction manager and a client commenting that the whole team was on the client's side; a trade contractor commenting on the impartiality of a construction manager being better than that of an architect; two consultants observing that there was a better match of skills to needs; two construction managers appreciated the equality of appointments; one consultant commenting on the honesty in the process and one observing that the role of a selfseeking main contractor was happily wiped out. Clearer contract structures were mentioned as a definite advantage. 
A construction manager thought that the extra management expertise was an advantage and this view was reinforced by a client who was positive about the ability to think through the construction process in terms of the client's requirements.

In terms of increased certainty, a consultant and a trade contractor mentioned prompt payment; a construction manager felt that there was greater certainty of delivery with this process; a consultant and a client both mentioned the extra speed and the cheaper final price by comparison with other procurement methods.

\section{Disadvantages}

The biggest disadvantage of CM is that it depends on a high degree of professionalism and experience; qualities which are unfortunately difficult to find in the UK construction industry. The other big issue was the uncertainty of the budget (one client, two construction managers and two consultants) and the perception of extra client risk (two clients and one consultant). However, this perception of extra risk should be tempered by the fact that it is only a result of clearer contract structures. In fact, claimed a client, there is more risk in other procurement methods because it is so well hidden.

The dangers associated with inexperienced clients were highlighted by two construction managers and one trade contractor. Added to this were disadvantages for the client of additional organisational cost, dangers of too many packages and the large number of contracts to administer.

For consultants, the disadvantages are with the difficulties of interface management, the fact that site exigencies dominate the process and the lack of clarity regarding the relationship between architect and construction manager. The duplication of paperwork was mentioned as a necessary corollary of the process. 
Trade contractors felt that CM demanded a large scale commitment from them; they reported difficulties of getting clients to talk directly to them in practice; the lack of an independent certifier and the visibility of weaker trade contractors.

A developer-client and a consultant introduced an interesting disadvantage: the fundability or saleability of a finished development in relation to the contingent liability handed on by the developer. In other procurement methods there is a clearer remedy for subsequent owners should defects or problems appear in the building. Basically, there are so many different parties in contract with the client on a CM development that the package of warranties and the assignment of liability is very complex by comparison with other procurement methods.

\section{Construction manager's agreement}

The contents of the contract should be an accurate reflection of the client's and construction manager's intentions. It is not merely a question of who takes on liability, but a wider question of how best the construction manager can serve the client. One thing must be realised from the outset: since the client is in direct contract with the trade contractors, the construction manager may not be able to have much influence over the terms and conditions of the trade contract-it all depends on the client.

\section{Integration with other consultants' agreements}

In general, consultants’ and construction managers’ agreements are integrated sets of documents (back-to-back), produced by clients. Sixteen responses (Figure 1) witness such integration. 


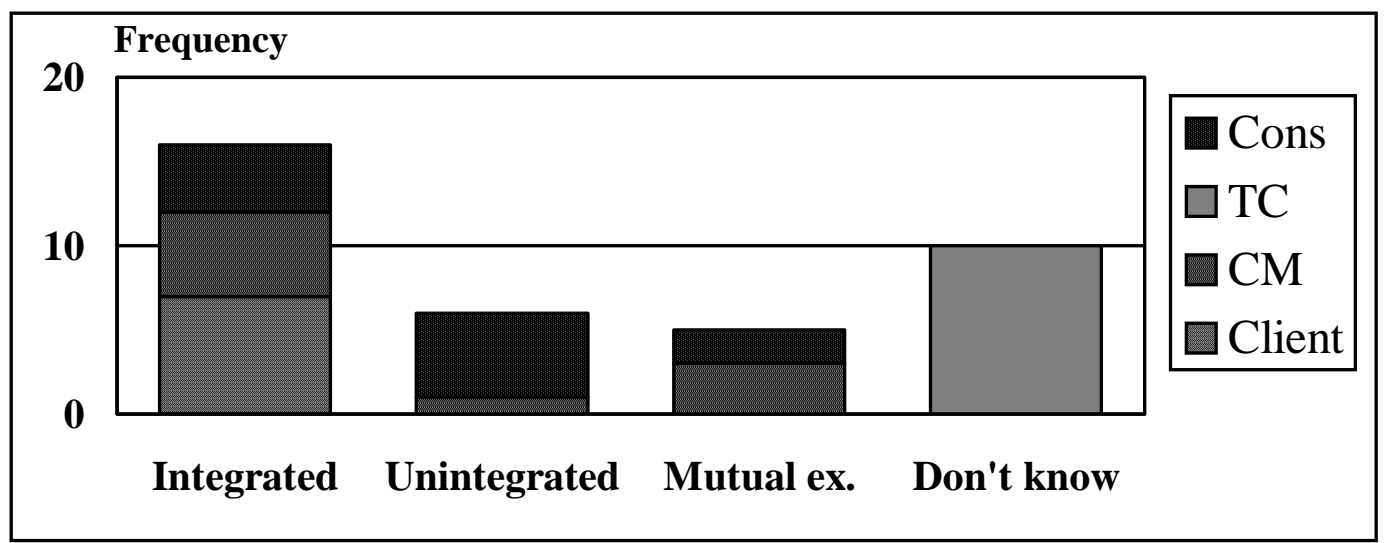

Figure 1: Relationships between terms of engagement and CM agreement

On the other hand, one construction manager and five consultants routinely see unmatched agreements being used. Five respondents spoke of the way that everyone on the team is given sight of each others' agreements (but not usually the section on fees), although no true integration was mentioned by these people. None of the trade contractors could answer this question because they had never seen any of the agreements on their projects.

A client spoke of adequate integration between the documents as "critical", bearing in mind that CM was not only a construction process but a design and construction process. Three construction managers and four consultants said that each of the team need to know the extent of authority and the precise obligations of the other members of the team. In some cases, a particular consultant (typically architect) sees the agreements for the rest of the team, but without reciprocation.

\section{Powers of the construction manager}

Interviewees were asked whether there were any issues for which the construction manager should not be the client's agent. The basic message from the research was that the authority of the construction manager should be unfettered, but there were qualifications on this. Clients did not want to hand over total control to the construction manager. Three of them wanted to ensure that the construction manager is not exclusively responsible for the project; 
the team includes the client and the other consultants. Another three wanted limits on what the construction manager could do without referring back to the client, in terms of variations, changes to the cost plan and letting packages. There were several concerns about the involvement of a construction manager with the design process. One client wished to preserve the distinction between construction management and design management. A fairly strong feeling was that the construction manager should only take a strategic management role, rather than taking an active part in the detailed co-ordination of the design. However, there was an equally strong view that limiting the extent of the construction manager's responsibilities was flying in the face of one of the basic defining characteristics of CM. One of the construction managers picked up this theme when he spoke of the need for acting responsibly, rather than for contractual responsibility. One of the construction managers felt that he should not manage the design team. Seven of the construction managers felt that there were no issues for which they should not be client's agent.

The trade contractors were more wary about having the construction manager act as agent in every respect. Although three answered "no", three echoed the idea that the team includes others and two felt strongly that the construction manager should not be an independent certifier and settler of disputes. One trade contractor felt that overall financial control of a project should always be in the hands of a PQS, not a construction manager. The role of the construction manager in issuing certificates is dealt with more fully, later in this paper.

Six of the consultants felt that there were no issues for which the construction manager should not act as client's agent. But two felt that the construction manager should not act as client's agent in making design changes and one wanted to ensure that the construction manager did not control the design or the cost, presumably preferring the traditional roles of architect and QS. 
It was interesting that the lawyers were concerned about the construction manager acting in the role of an independent certifier, as architects had done in more traditional projects. One felt that this should happen, and that in this case the construction manager could not act as agent, the other felt that the construction manager should not certify at all, in which case the construction manager could only be an agent of the client. Presumably, the lawyers have a narrower and stricter definition of the word agent; the other respondents were much less clear in their responses because the term was used more loosely.

Despite the fact that the questions only related to $\mathrm{CM}$, one construction manager and one trade contractor felt it necessary to say that the construction manager should not be in the payment chain.

\section{The role of the construction manager during design development}

There are two aspects of the construction manager's role in the procurement of design. First, the extent to which the construction manager is involved with the procurement of the design. In eight cases, the construction manager had a role in choosing designers. In some of these cases, the construction manager's role was one of actively choosing the designers, but usually the role was advisory only. There seems to be an overlap between the client's need to govern the choice of design consultants and the construction manager's need to govern the choice about design input from trade contractors.

The second issue is the extent to which the construction manager co-ordinates and manages the design development process. Seventeen of the respondents said that the construction manager is responsible for managing the process, although this was not unequivocal because many people qualified this by saying that the construction manager's role was not to dominate the design team, but to contribute by co-ordinating the design input of the trade 
contractors. Clearly, the construction manager has a role in contributing construction advice and in advising on the definition of trade contractors' design scope. But there were mixed views about the extent to which this strays into the sphere of managing the design process.

This issue was another one in which the trade contractors felt that they had no advice or opinion to offer, with seven trade contractors either declining to offer a clear view or stating that they had no knowledge of these aspects.

\section{Trade contractor's agreement}

Many of the provisions in trade contracts are very similar to provisions in main contracts or sub-contracts. However, there are issues which need to be dealt with uniquely for CM projects, and only those issues are considered here. These issues typically arise because there is no main contractor.

\section{Trade contractor design input}

Design integration is probably the single most problematic feature of CM projects. There are a variety of means for achieving it, and three themes emerged from the interviews.

\section{SEPARATE DESIGN CONTRACTS FOR TRADE CONTRACTORS}

Twenty three respondents said that they never used a separate design contract, and five said that one was used occasionally. Two respondents were adamant that design should never be part of a trade contract (one architect and one trade contractor); they felt that to incorporate design into trade contracts is to dilute and distort the proper interaction in the design team.

Defining the precise nature of a trade contractor's design responsibility is a big problem identified by nine respondents (a client, four architects, three trade contractors and a quantity 
surveyor). One trade contractor felt that trade contractors tend to be responsible for design development but get “saddled” with far more than that due to architects' lack of diligence.

There are two types of trade contract—with and without design. (Trade contracts for specialists with a design input are effectively Design-Build contracts.) Both types are needed in full and minor versions.

\section{TWO-STAGE TENDERING}

Two-stage tendering is rarely used. Nine respondents said that it was never used; three said it was occasionally used and only one said that it was used often. One client felt that if the design is so incomplete as to warrant two-stage tendering, then it should not be bid. A construction manager said that the aim of two stage tendering was rarely clear. A trade contractor said that it would only be considered if he could be sure of being paid for the second stage; otherwise this is design development for free (a problem that was often mentioned by trade contractors). A QS felt that two-stage tendering was not sufficiently competitive, but an architect took a different stance, saying that it ought to be used to ensure that trade contractors realise the extent of their design responsibility and tender (and get paid) properly for it.

\section{PERFORMANCE SPECIFICATIONS}

Again, a fairly consistent message comes across. Nineteen respondents said that performance specifications were used extensively; five said occasionally and two said they were used only where they were appropriate. Three of the respondents emphasised that performance specifications are often badly written and great care is needed in their preparation. One client thought performance specifications acceptable provided that they do not let the design team “off the hook”. Finally, one construction manager asserted that bills of quantity should definitely be avoided. 


\section{Common user equipment}

When asked about attendances and common user equipment, it turned out that the approaches to this issue are diverse. Five of the respondents definitely leave this issue to the demands of the particular project and six said that it could be provided either by the construction manager or by a trade contractor . Nine respondents said that each trade contract spells out what is available and what the trade contractor will provide , although it was not clear whether provision was by the construction manager or part of a separate package. Of these, two commented that the full needs for equipment were rarely thought through properly and as a result practice was messy. Six people said that the equipment was provided by the construction manager, as part of the preliminaries. By contrast eleven said that there was a separate trade contract for common user equipment. An architect referred specifically to a multi-service gang paid by the client.

One trade contractor quotes on the basis that everything necessary will be provided, whereas four trade contractors and an architect assume that nothing will be provided, and this was backed up by four others who said that any trade contractor requirements are assumed to be mentioned in their tender.

An architect felt that this issue was normally dealt with very badly because there seems to be an assumption that each trade contractor brings its own equipment.

Some respondents commented on charging; one client saying that trade contractors are charged for their use of equipment (and credited if they do not use it); a construction manager commenting that trade contractors are not charged for their use; and two trade contractors said that if one trade contractor makes equipment available for another then he is to send the bill directly to the trade contractor. 


\section{Interim payments}

Interim payments to trade contractors could be based on valuations of work done at regular intervals, or on stage payments tied to milestone events. Interviewees were asked which they typically encountered in practice and Figure 2 summarises their responses.

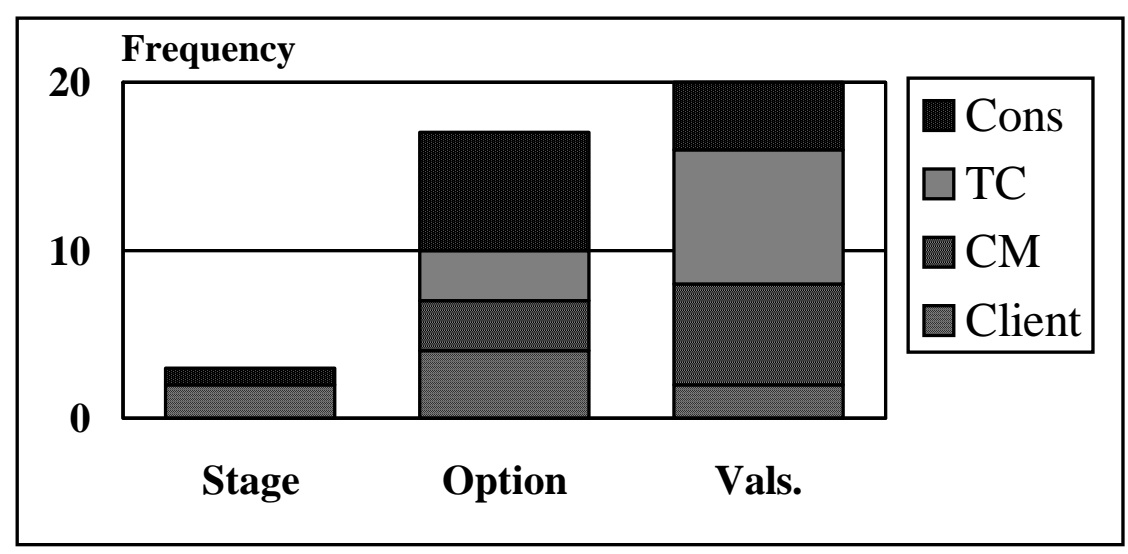

Figure 2: Method of interim payment

Three of the respondents tend to see stage payments most commonly; seventeen said that both methods were routinely used depending upon the circumstances of the package; and twenty saw regular valuations of work (almost) always.

One client commented that milestone payments allow payment only for real value to the client, and two other clients said that they linked payment to clearly identifiable goals. However, as one trade contractor pointed out, there are real problems with identifying what constitutes completion of a stage. An architect pointed out that interim valuations bring many problems to light at an early opportunity because of the discipline of routinely examining work done so that it can be signed off for payment.

\section{Certification}

Certificates that would have been issued by an architect under more traditional forms of contract are dealt with in a variety of ways in current CM practice, as shown in Figure 3. 
Interviewees were asked whether the construction manager signed certificates and about the extent to which members of the design team were involved.

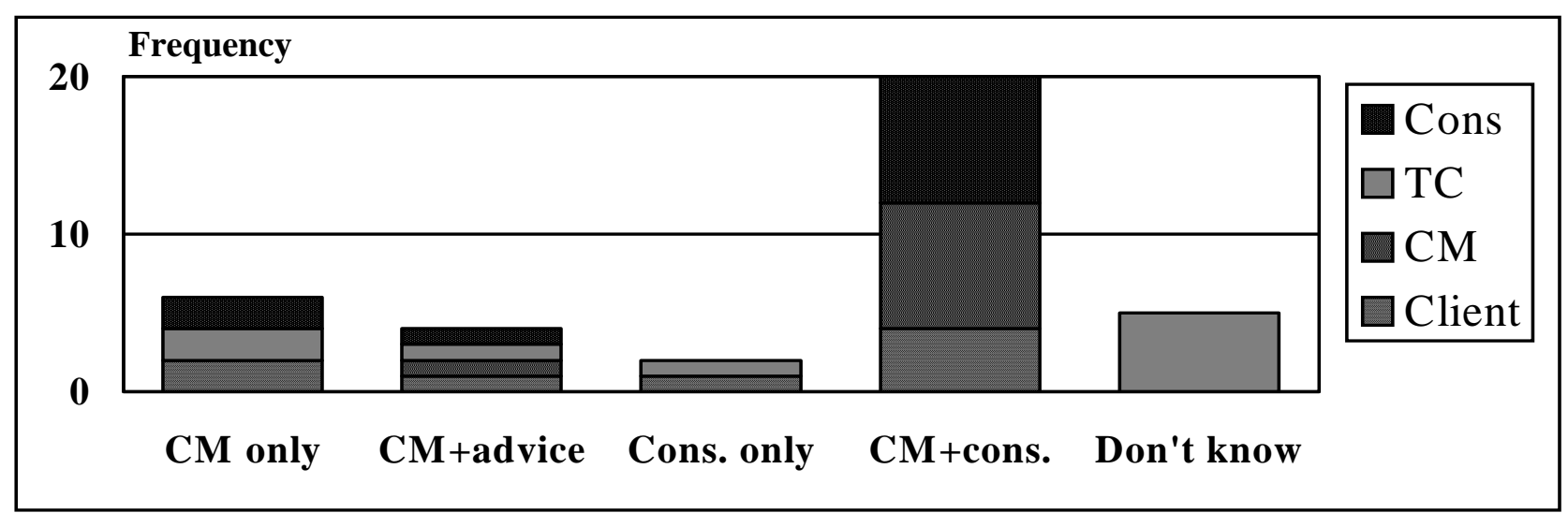

Figure 3: Who signs the certificates?

In the majority of cases the construction manager signs the certificates and they are countersigned by the relevant member of the design team. In four cases, certificates are signed by the construction manager, who has an obligation to consult the relevant members of the design team. In seven cases, certificates are signed and issued by construction manager alone. In two case, certificates are signed by the "appropriate consultant” alone. One surprising finding was that five of the trade contractors did not know who signed the certificates that enabled them to be paid.

Two clients pointed out that an architect's (or QS's) signature is needed on certificates because of the requirements of the funders of the project.

It is the vexed issue of certification by the construction manager that brought CM before the courts in the case of Redpath Dorman Long v. Rosehaugh Stanhope ${ }^{3}$. This case was a complicated legal battle over whether the construction manager could make a bona fide

\footnotetext{
${ }^{3}$ Rosehaugh Stanhope Properties (Broadgate Phase 6) plc and Rosehaugh Stanhope Properties (Broadgate Phase 7) plc v Redpath Dorman Long (1990) 50 BLR 69, 6 Const LJ 309, [1990]BLM (August) 10.
} 
estimate of how much of a trade contractor's payment could be withheld in the absence of any proof of the trade contractor's guilt. The decision in that case rendered the construction manager powerless to deduct monies from defaulting trade contractors until and unless a trade contractor either admitted or could be proved to have caused the delay which led to the client's loss.

\section{Acceleration}

Some contracts include provisions for acceleration of a trade contract, even though they rarely provide more than a procedure for negotiating a new completion date and a revised price; an option which is always open to contracting parties anyway. Our research interviews sought to discover whether acceleration clauses were included and if so, whether the trade contractor had a right of objection. 


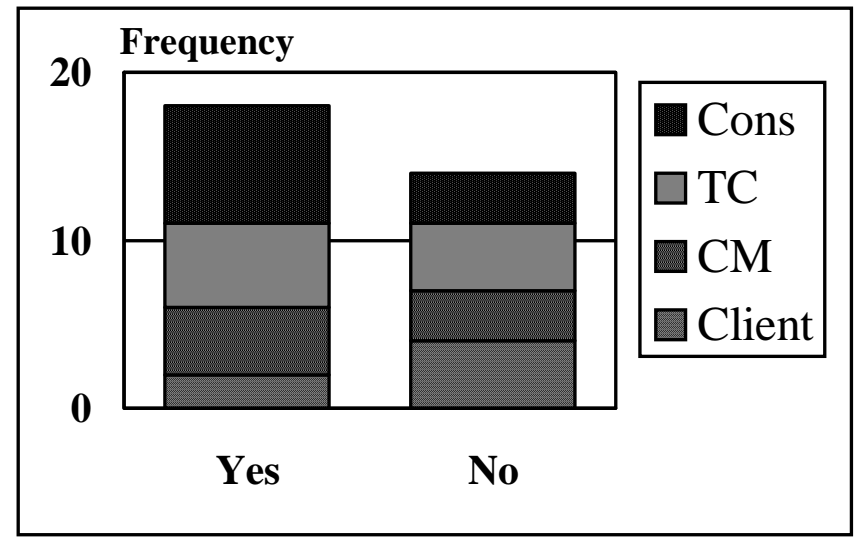

Figure 4: Acceleration clause provided?

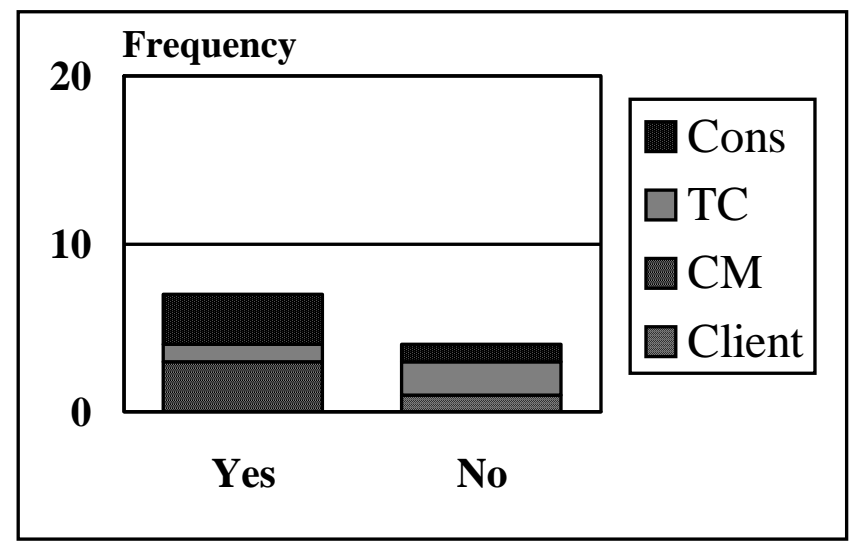

Figure 5: Right of objection?

Figure 4 shows that eighteen people said that they routinely included an acceleration clause and fourteen did not. Many respondents were not forthcoming about the trade contractor's right of objection, but seven said that there was typically such a right and four said that there wasn’t (Figure 5).

One client found the whole idea of acceleration contrary to good practice. When putting out packages to bid, proposals for speeding up the process are sought. The construction manager ensures that there is no slack, incorporating forward and backward float into all packages.

Thus, the ability to accelerate is built into the programme through good management practice. 
A project manager also found that programming is generally too tight and carefully planned to make acceleration a plausible option.

Although three people explicitly stated that an acceleration clause was unnecessary because of the normal right to re-negotiate the trade contractors' programme, a QS took a different view; that acceleration must be an explicit provision.

The two lawyers that were interviewed held opposite views in this respect. The first sometimes saw acceleration, but never on the basis of a unilateral order whereas the second saw it as an essential provision, stressing that there should be no right of objection except in cases of practical impossibility - almost everything can be compensated under the contract.

\section{Dispute resolution}

The topic of dispute resolution was addressed by asking people how they typically dealt with the settlement of disputes in trade contracts. The responses are summarised in Figure 6, which shows how many times each procedure was mentioned, even though many respondents mentioned two or three procedures routinely being used. 


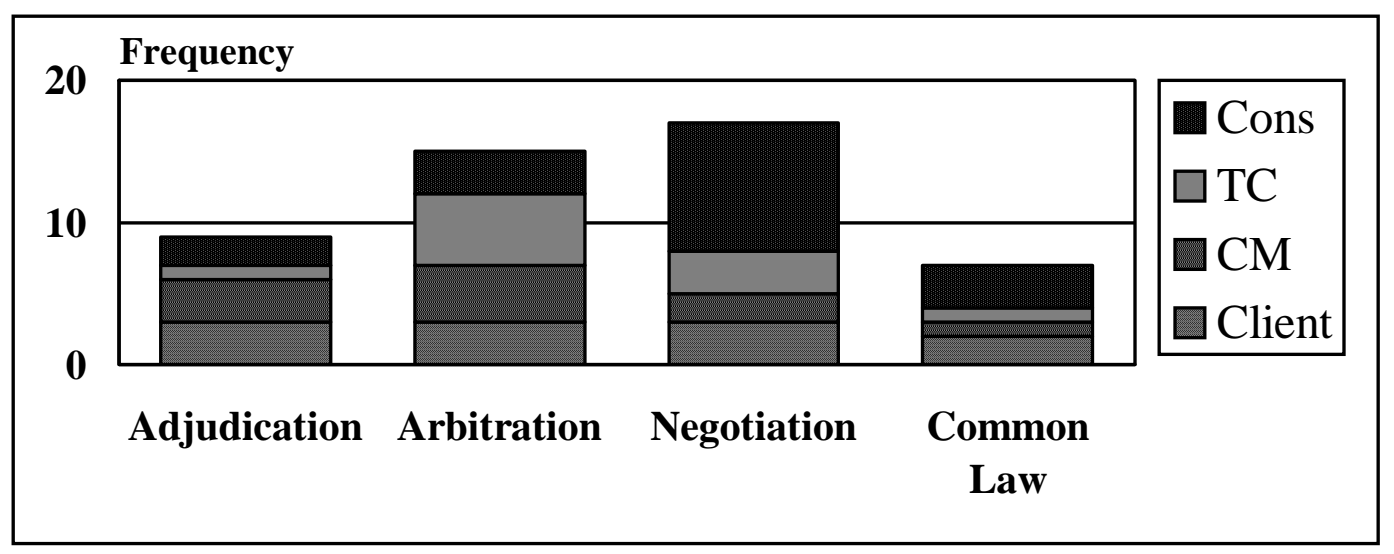

Figure 6: Dispute resolution procedures

A project manager said that disputes were negotiated as they occurred, and that this was backed up with arbitration and litigation. The most common way to deal with disputes is to negotiate before they escalate into some kind of formal procedure. Many respondents spoke enthusiastically about this being one of the advantages of CM, although it is an aspect that arises from the management philosophy, rather than the contractual provisions. Some of these did not mention the presence or absence of any clause. Many of those that did mention arbitration and adjudication clauses said that they had never exercised such provisions. A few said that they had never experienced any claims either, despite continuous involvement with construction.

Nine of the respondents said that they used adjudication clauses, although one said that this only applied to disputes over set-off. Arbitration was a possibility in fifteen cases. One architect said that arbitration was really of no use, being too expensive and not taken seriously. This view was shared to some extent by seven others who dismissed arbitration for various reasons. Seven people referred to various aspects of common law; some preferring to rely upon litigation as the only reliable procedure; or saying that a writ is a very useful way of convincing people that negotiation will be worthwhile; or as the next step after a failed negotiation in the absence of arbitration. 


\section{Set-off}

There is widespread use of set-off and it seems to be acceptable to all parties, with thirty four people clearly stating that they use it. Some went as far as saying that it would be unfair to exclude the client's rights of set off. Some respondents, especially the trade contractors, had provisos; one that claims should be properly investigated, another that set-off operated within a clear set of rules, others that spurious counter-claims were an abuse of the provisions and care was needed to prevent this.

Only one respondent thought it a good idea to keep claims against trade contractors out of the normal payment regime. Two respondents thought that these issues should be subject to an independent decision by the construction manager.

In addition to eliciting views about set-off, interviewees were also asked if disputes about setoff should be referred to an adjudicator for a binding decision. Figure 7 summarises these views.

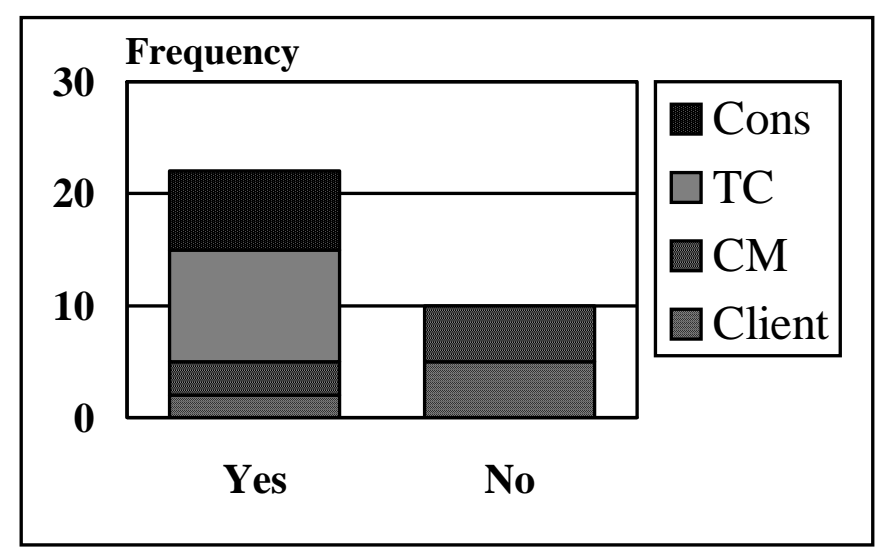

Figure 7: Disputes for binding adjudication?

In response to this question, most respondents said yes. There were some interesting comments made about adjudication: one client is in favour of adjudication, but only where a proposed set-off is disputed-i.e. not an automatic reference to the adjudicator; another client 
feels that outsiders with no knowledge of the job are a waste of time and money. Speed in resolution is essential. Any procedure which takes time is doomed to failure on a fast job; a third client feels that any adjudicator would be perceived by the trade contractors as on the side of the client; a client and a construction manager felt that automatic recourse to adjudication is, in effect, an admission of management failure.

\section{Final certificate}

The interviewees were asked about how they typically deal with final certification in trade contracts, in terms of the extent to which trade contractors await final project completion.

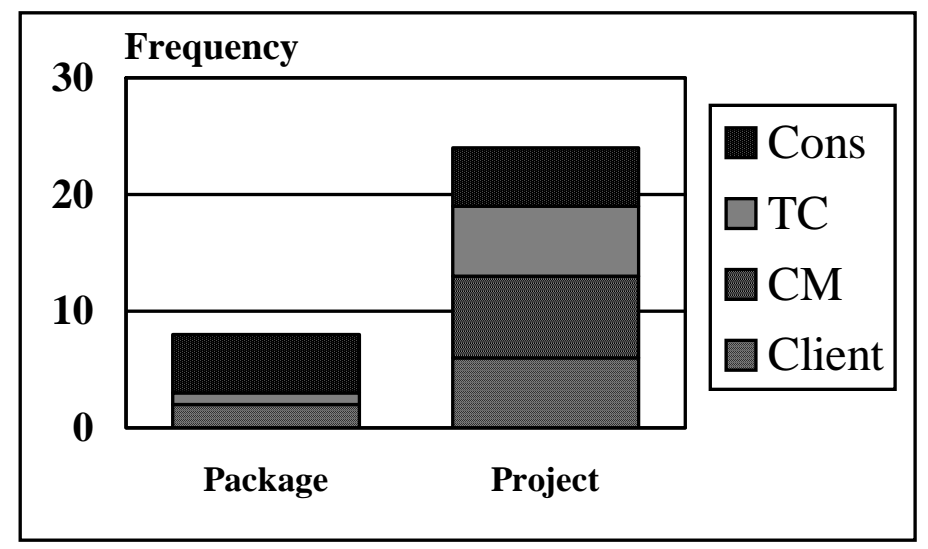

Figure 8: Final certification by package or project?

The question elicited a fairly strong response indicating that typically trade contractors have to await final project completion before their packages are certified as finished (Figure 8), although in nearly all cases each package has its own practical completion certificate.

Two clients pointed out that in many projects most trades finish simultaneously anyway, and the few that finish early can be dealt with individually. Indeed, one construction manager and one trade contractor discussed a process of negotiation based upon certifying work as complete only when it is finished and possibly withholding some retention only where there was a perceived need for it, subject to agreement between client, construction manager and 
trade contractor. Another client used a common final completion as a contractual provision, but routinely negotiated earlier settlement and final account for most packages as they were finished with. In this case the client did not want the practice to become a contractual obligation because he would lose the lever that he currently had.

A lawyer said that in terms of liability for delay the trade contractor does not await final project completion. Perhaps there is a difference between practical completion of a trade contract and practical completion of a project. The only significance in project completion for the trade contractor is that before final completion he might be asked to remedy damage to his work that has been caused by others (in exchange for pay) and after completion the trade contractor's only obligation is to remedy defects at his own expense.

\section{Defects liability periods}

Following on from the question about final certification, interviewees were asked about how a trade contractor's liability for defects is typically dealt with.

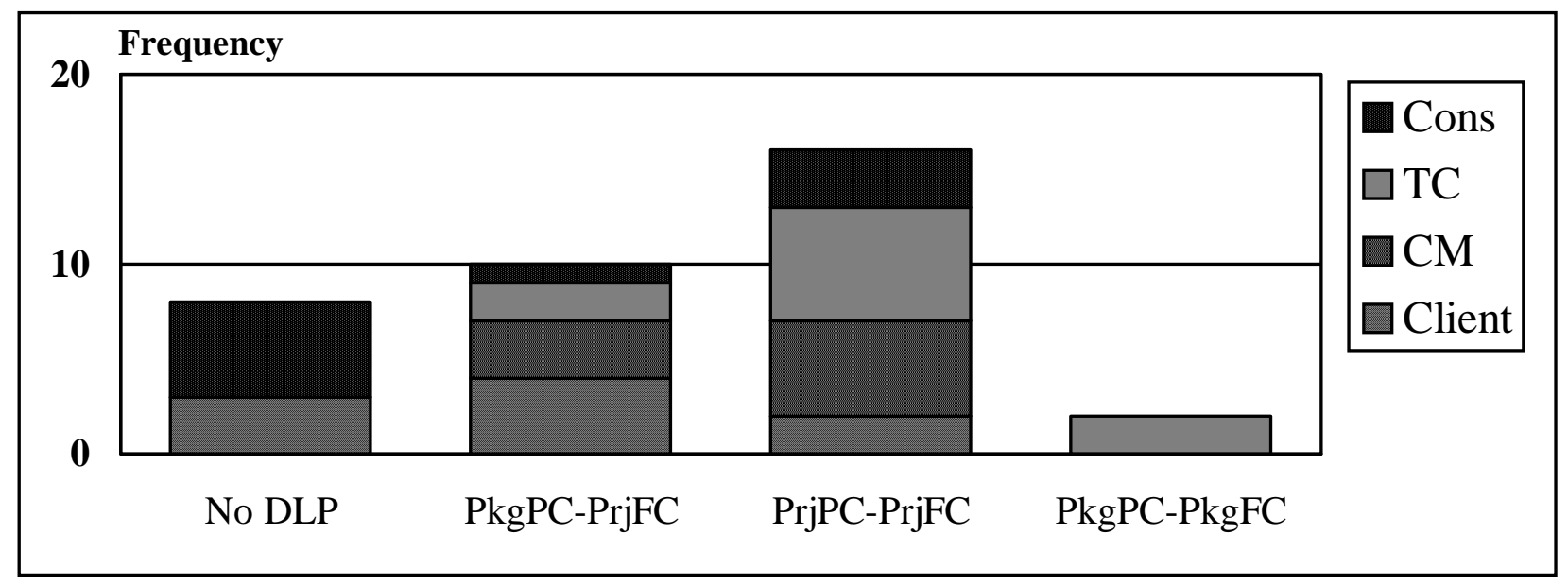

Figure 9: Timing of defects liability periods

Sixteen respondents, as shown in Figure 9, said that their practice was to have one defects liability period for the whole project. Two clients had an option to sign off initial packages 
early. Another spoke of a trade completion certificate which released the trade contractor from site but not from liability for protection of work. Ten respondents had defects liability commencing at the completion of the package and continuing to final completion of the project. Only two trade contractors had individual package DLPs with independent final certification.

Of the respondents who did not use DLPs, one client uses construct and maintain contracts (another is contemplating their use); three people simply rely on common law remedies for breach of contract; another client has no DLP, but retains specific amounts for specific items of outstanding work or unusually risky aspects, with the agreement of the trade contractor (this is negotiated, there is no clause).

Protection of completed work was mentioned by eight respondents. The difficulty is the time between practical completion of the package and practical completion of the project. Two solutions were offered; a QS spoke of a special trade contractor whose sole responsibility was to protect everyone else's work-if access were needed, the protection trade contractor would remove and then replace protection. An architect spoke of a detailed photographic and written record which is made on completion of a package so that the cause of defects could clearly be identified as defects or damage to completed work.

\section{Damages for late completion}

Finally, interviewees were asked about how they typically dealt with the issue of liability for late completion in the trade contracts. Their answers are summarised in Figure 10. 


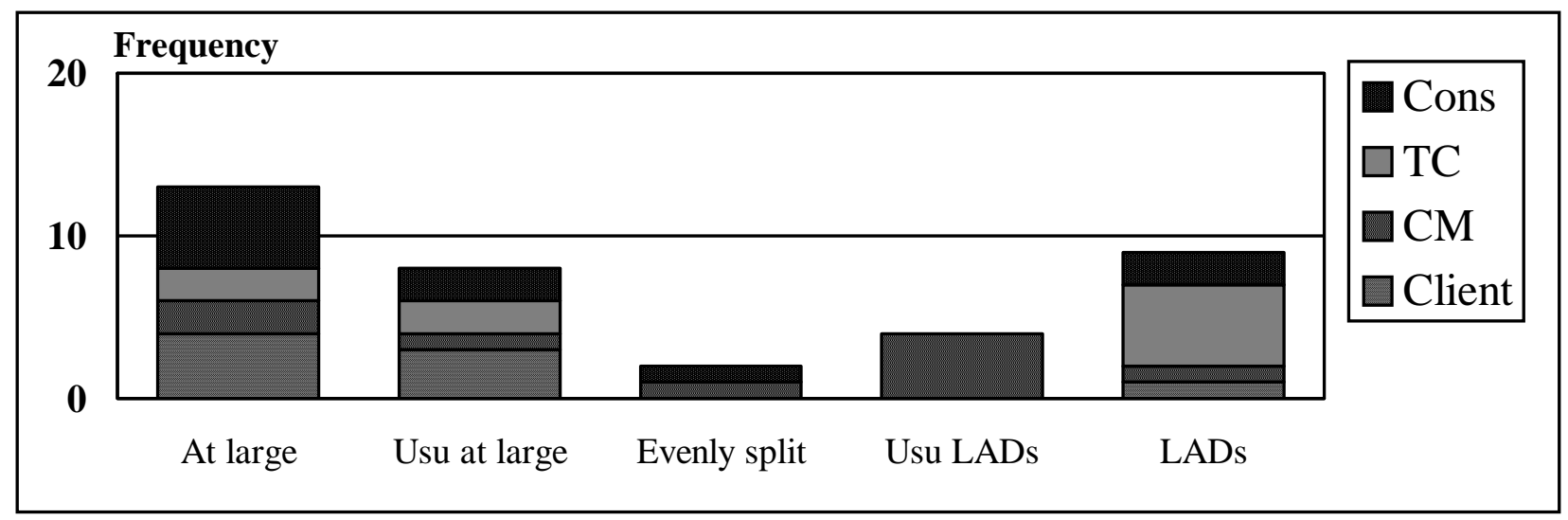

Figure 10: Trade contractors' liability for late completion

There are two basic options, liquidated damages or damages at large. Both are routinely specified in contract documents. Neither are actually levied in practice, except very rarely, as the construction manager has a primary role to play in ensuring that delays do not accumulate. Whether by clever programming, which includes realistic floats, or by strong management and control, or a mixture, most people reported few problems of delay.

Trade contractors prefer the certainty offered by liquidated damages; one turns down projects where damages are left at large. Figure 10 shows that the most common practice favours unliquidated damages; 21 respondents see damages at large always or usually, whereas only 12 see liquidated damages always or usually.

\section{Conclusion}

There are few issues that have been faced by the courts in direct relationship to construction management contracts. This is for two reasons. First, CM has not been used for long in this country and second, those who have used it have been highly experienced people with a strong desire to preserve good business relationships. The emergence of standard forms of contract may change this. 
Contractual issues relating to CM alone are primarily related to the absence of a main contractor and secondarily related to the interface between design and management. Since there are so few experienced practitioners in this field, they frequently encounter each other and reasonable degree of consensus in practice has emerged. The final point to emphasise must be that $\mathrm{CM}$ is more a management philosophy than a contract structure. The management philosophy must come first. Legal issues are not important where there is a will to negotiate and resolve differences of opinion before they become "festering disputes".

\section{References}

Banwell, G.H. (1964) The placing and management of contracts for building and civil engineering works. HMSO; London.

Bingham, A (1992) A case to get you all steamed up. Building 3 Jul, 36.

Chappell, D (1989) Is it worth suing an architect? Building Today 2 Feb, 24-25

Greenwood, D.J. (1993) Contractual arrangements and conditions of contract for the engagement of specialist engineering contractors for construction projects. CASEC; London.

Hughes, W.P., Gray, C. And Murdoch, J. (1995) Effective specialist and trade contracting. CIRIA (in press)

Institution of Civil Engineers (1994) New Engineering Contract. Thomas Telford; London.

Latham, M. (1994) Constructing the team: final report of the government/industry review of procurement and contractual arrangements in the UK construction industry. HMSO; London.

Murdoch, J R and Hughes, W P (1996) Construction contracts: law and management. 2ed. Spon’s; London.

Rougvie, A (1987) Project evaluation and development. Mitchell's; London. 